\title{
"SOBRE DISCURSOS Y RACIONALIDAD FEMENINA MEDIEVAL": REFLEXIONES EN TORNO A LA MUJER EN EL MUNDO MEDIEVAL: SIGLOS X AL XIII DE MARIA ELENA CHICO DE BORJA
}

Virginia Aspe Armella

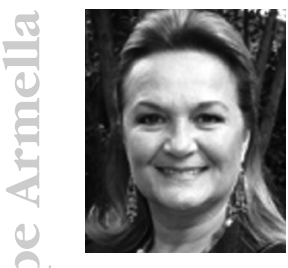

Profesora titular de Filosofía en México. Facultad de Filosofía de la Universidad Panamericana. Investigador Nivel 2. Miembro de la Academia Mexicana de Doctores en Ciencias Humanas y Sociales. Ha publicado diversos artículos en revistas especializadas y de divulgación, además de varios libros. Entre sus trabajos más destacados: Las aporías fundamentales del periodo novohispano, CONACULTA (2002); El concepto de técnica, arte y producción en la filosofía de Aristóteles, FCE (1993); Perennidad y apertura de Aristóteles: Reflexiones poéticas $y$ de incidencia mexicana, Editorial Cruz, O. (2004)

Correo electrónico: virginiaaspe@yahoo.com.mx 


\section{INTRODUCCIÓN}

Enhorabuena por este libro ${ }^{1}$ que aborda un tema relevante en la condición contemporánea, en especial porque no se había publicado en México una obra así.

La pertinencia de esta publicación se debe a que plantea la cuestión del género. En el siglo que vivimos, el tema de la mujer se formula casi siempre con categorías liberales, y la investigación de María Elena Chico aporta un enfoque diverso al partir de las preguntas: ¿cuál ha sido el papel de la mujer en otras épocas?, ¿cuál fue su protagonismo y rol durante la Edad Media?, ¿qué caracterizó su contribución?

Además de ser pertinente el tema —el papel de la mujeres muy importante la época que elige y más todavía la agudeza de su planteamiento; en el siglo XX, el discurso de género se abordó siempre con categorías marxistas de "opresión", "Subordinación" e incluso nulificación de la mujer. María Elena parte de la tesis contraria: desea probar que, aun en la Edad Media, hubo roles femeninos protagónicos, capaces de superar los patrones culturales de la época.

Por encima de todo, este libro es un "canto a la mujer", una defensa de las capacidades femeninas, de su facultad para superar el entorno o de asumirlo con ingenio y creatividad.

Estamos frente a una obra muy interesante cuyo objetivo es probar cómo el cristianismo intentó romper con la subordinación de la mujer al varón, que implicaba el patriarcado pagano.

Chico de Borja, M.E. La Mujer en el mundo medieval. Siglos X a XIII., Ed. Porrúa., México., 2006. 
María Elena parte de la unidad del acto creador divino — tal como se relata en el Génesis_- para sostener la igualdad radical cristiana entre hombre y mujer, seguida por el pasaje de Pablo de Tarso: "Ya no hay judío, ni griego, ni varón, ni mujer, ni esclavo, ni libre, ya que todos somos uno en Cristo Jesús".

La tesis que propone la investigación de la doctora Chico es que, aunque el cristianismo no logró esto inmediatamente en la práctica (debido a condicionamientos culturales), sí atenuó las diferencias gracias al concepto cristiano de creación ex nibilo, y de hombre y mujer Imago Dei, conceptos ausentes de la tradición filosófica pagana que recrudecieron las diferencias de género.

María Elena sostiene que el derecho romano tendió a relegar a la mujer en el ámbito privado - considerando este período como el primer nivel del deterioro conceptual de lo femenino-, exacerbado a partir del siglo XIV en el que la progresiva influencia del derecho romano se combina con los principios de la modernidad y el posterior código napoleónico de 1804.

En mi opinión, esta decadencia comenzó desde el siglo XII con la incorporación árabe de las obras de Aristóteles en la Universidad de París, pues ya en Tomás de Aquino el tema de la mujer aparece con categorías de subordinación y minusvalía frente al hombre.

Para demostrar su planteamiento, la autora rastrea en la primera parte del libro la evolución de la situación de la mujer en la legislación medieval que contó con: 
- Antecedentes judeocristianos y grecorromanos.

- Una poderosa influencia del derecho germano, de la legislación visigoda y anglosajona.

Considera que, en la Alta Edad Media, la evolución de la mujer mejora positivamente gracias al reconocimiento de su capacidad jurídica civil en cuanto:

- A las cuestiones matrimoniales;

- las testamentarias;

- y para el derecho de acusaciones de adulterio.

Nos señala que esto se observa en la obra de Las Partidas de Alfonso X, el sabio, donde se prueba ya la relación recíproca de hombre y mujer.

Dos puntos clave que contribuyeron a esta igualdad fueron la cédula conyugal de la pareja y la instalación de la casa con la mujer como centro. Es entonces que la mujer se erige como madre y educadora, y al aparecer las guerras y las cruzadas alcanza protagonismo público.

El énfasis en la vida cotidiana — casa y crianza - es, quizás, lo que la hace propensa a ciertos oficios en la época medieval:

- Administración de hospitales.

- Intereses medicinales, terapéuticos y curativos.

- Literatura.

- Música.

— Dirección de abadías, monasterios, leprosarios... 
Funciones, todas éstas, relacionadas con la intuición y el ámbito práctico experiencial que, en mi opinión, van configurando sus categorías racionales.

La obra rastrea estas contribuciones y compara la concepción pagana y la cristiana. De acuerdo a la autora, el punto clave radica en que, a partir de San Pablo, se considera que puesto que no hay subordinación de Cristo respecto del Padre, tampoco existe inferioridad de la naturaleza femenina frente a la del varón. María Elena considera las diferencias entre el hombre y la mujer en relación horizontal, de igualdad complementaria, no en una relación vertical, de superioridad e inferioridad. Todo el desarrollo de su libro se dedica a probar lo anterior, desde el ámbito historiográfico y literario.

Ahora bien, a lo largo de la investigación, María Elena se pregunta: si esto es así, ¿por qué no se llevó a la práctica a lo largo de la historia medieval? Ella considera que en las tres etapas posteriores del cristianismo —después de Jesús y la primera de los apóstoles-, la interpretación de la mujer y su valoración frente al hombre evolucionó de modo diverso a como la interpretó Pablo, porque desde los padres apostólicos, el cristianismo integró a filosofías paganas y, con ellas, cambió el modo de concebir la naturaleza humana.

En mi opinión, aunque es verdad que el cristianismo se integró al pensamiento pagano, no creo que ésta haya sido la causa de la desviación, pues precisamente una de las grandezas del cristianismo ha sido su incorporación de lo pagano (de allí su peculiar maleabilidad y apertura); "católico" quiere decir universal, porque se abre a todos, y el cristianismo estaba preparado para formularse con argumentaciones racionales no 
religiosas en los temas de antropología, ciencia y ley natural. Coincido con María Elena en que, a lo largo de la historia de las ideas, existen desviaciones en la interpretación de la mujer y su valía desde algunos intérpretes cristianos del inicio, un ejemplo claro es la incorporación de Tomás a Aristóteles.

María Elena demuestra que en San Jerónimo, Padre de la Iglesia latina, ya hay una inclusión respetable del papel de la mujer y que también San Agustín sigue el habeas paulino pues, para él, hombre y mujer fueron creados Imago Dei, y en Dios no hay sexo ni diferencia alguna entre las personas, de tal manera que les rige la justicia y del mismo modo debe el hombre a la mujer y la mujer debe al hombre.

En la obra De Bonum Coniugiorium y en De Nuptia et Concupistentia señala Agustín que el marido dé el débito a la mujer y la mujer a su marido; que es el marido quien tiene poder sobre el cuerpo de ella y ella poder sobre el cuerpo de él, y que no hay que negarse mutuamente lo que uno debe al otro. Nótese como predica Agustín de modo horizontal, y no de dominio los derechos y los deberes entre hombre y mujer.

¿En dónde vino pues, en el cristianismo, el cambio en la relación horizontal entre hombre y mujer? María Elena apuesta el origen del problema a una tesis de antropología filosófica aristotélica que interpretaron algunos comentadores cristianos; se trata de la tesis de la interpretación dicotómica y tricotómica del hombre. Nos explica que Pitágoras, Platón, Aristóteles, Plotino y Filón consideraban al compuesto por tres realidades: cuerpo, alma y espíritu —soma, psyché y nous—. En esta interpretación, alma y espíritu eran un binomio psicológico, por lo que el ser humano se entendía como compuesto 
por dos miembros o principios pero por una doble consideración psicológica: el alma y el intelecto (o nous). Pero cuando Orígenes y San Agustín involucran un principio psicológico más, el pneuma o soplo, se produce la inevitable confusión de ya no situar al hombre en el mundo - como lo hacía la interpretación dicotómica de alma y cuerpo unidos-, sino sólo percibirlo como un ente moral.

Desde Beda, siglo VII (y yo agregaría a María Elena, desde Isidoro de Sevilla, siglo VI, que influyó en Beda el Venerable), hasta el siglo XII, un bloque cristiano concibió al hombre en el mundo pero otra línea más fuerte privilegió esta interpretación tricotómica de San Agustín y el estoicismo. La interpretación dual de la psicología humana —nous o intelecto y pneuma o soplo- dio lugar a una desviación misógina, pues si en los seres humanos la psicología era diferente o compuesta, una tenía que imperar sobre la otra y ejercer subordinación.

En las siguientes páginas del libro, y siguiendo a Saranyana, María Elena rastrea las dos vías de interpretación, pues la última considera a la mujer como lo regido, y al hombre como quien rige; es decir, en vez de interpretar la relación entre hombre y mujer de modo horizontal, lo hacen de modo vertical.

Para la autora, el siglo XII es el triunfo de la interpretación dicotómica, y el XIII ya usa el binomio psicológico que desprecia a la mujer.

En el Capítulo III, se exponen los fundamentos de la organización medieval; en el IV, se describe el papel de la mujer 
en la Edad Media según las leyes, la organización social, economía, literatura y el arte para, en el capítulo V, exponer estos aspectos a la luz de las mismas tesis, y terminar en el capítulo VI con un análisis de su protagonismo político. En el capítulo VII, se eligen cuatro casos femeninos ejemplares para redondear la exposición.

De este balance, un punto merece señalarse: parece ser que la vía dicotómica de la antropología es una lectura neoplatónica —ya sea de Platón o de la interpretación estoica de la antropología aristotélica- y que el error provino del helenismo, es decir, de la incorporación latina del pensamiento pagano griego. Esta tesis aportaría a la propuesta de María Elena que los romanos interpretaron así lo griego y que los cristianos incorporaron esta interpretación falaz a su propio saber. Pero el hecho también prueba otra vía neoplatónica que María Elena no investiga: cuando el emperador romano cerró todas las escuelas griegas de filosofía en Atenas, durante el siglo $\mathrm{V}$, el helenismo se desplazó hacia oriente con esa interpretación de autores como Alejandro de Afrodisia. Estos filósofos llegaron primero a Mesopotamia, después a Persia y Siria para, en el siglo VII, desplazarse a Toledo (España), y en el siglo XII pasar a la Universidad de París heredando esta postura. Fue allí donde, en el siglo XIII, Tomás de Aquino bebería de esta interpretación. Esto explicaría por qué en el siglo XIII, la Universidad de París ya no tenía la interpretación horizontal del hombre y la mujer. No olvidemos que Tomás de Aquino siguió en mucho los comentarios árabes de las obras de Aristóteles (por ejemplo de Avicena, Averroes y Alkindi y Alfarabi). En la Universidad Panamericana tenemos al especialista mexicano más relevante de este tema, el doctor Luis Xavier López-Farjeat, 
quien coincide con la interpretación que aquí señalo; este punto verificaría de modo redondo vía oriente y occidente, la tesis de María Elena en su libro.

La tesis que subyace a lo largo de toda la obra de la autora es que, en realidad, el hombre y la mujer son distintos, pero poseen una relación de igualdad horizontal —no de subordinación sino de complemento-. Ella lo prueba señalando cómo, a pesar de que hombre y mujer se concebían diversos culturalmente, la mujer fue capaz de encontrar su propio espacio y autonomía, sin rechazar el rol sociocultual que la época le otorgó. Ésta me parece la cuestión más profunda de la presente obra.

El libro de Chico Pardo presenta modelos de mujer típicamente subordinados — de manera vertical—: mujeres cuyo poder está en ser hijas, esposas o madres de un hombre poderoso, rico o importante (rey, Papa, príncipe o algún protagónico varón), y que sin embargo, hacen que se manifieste la interpretación binaria según su desempeño y decisiones.

María Elena expone siempre en su relato un modelo social típicamente medieval, donde el hombre es el protagonista de la esfera pública y la mujer se halla en casa pero, debido a alguna circunstancia extraordinaria, debe relevar temporalmente las funciones masculinas (por una guerra, enfermedad o táctica política). Cuando esto ocurre - podríamos afirmar: cuando ocurre este fenómeno medieval - acontece una equidad de género casual en el rol medieval. Resulta que las mujeres tienen la capacidad de desempeñar esa función y, en ocasiones, incluso de superarla. 
Alguna feminista señalaría: sí, pero allí la mujer fue un mero relevo, una sustituta. María Elena ha ido al fondo antropológico — no al rol cultural historiográfico- probando las mismas capacidades antropológicas, a pesar de la diversidad en roles y tendencias. Descubre y señala papeles típicos femeninos para penetrar más a fondo y mostrar una tendencia diversificada entre los dos géneros. La mujer aparece en su relato como puente: siempre es un enlace, un medio entre diversos, un ser capaz de suplir poquedades con una intelección distinta que privilegia la visión frente a razonamientos deductivos. Esto se observa en el último capítulo de la obra donde se analizan distintas mujeres a través de su conducta política y de sus escritos literarios:

- Conductas políticas de Leonor de Aquitania y Blanca de Castilla.

- Textos literarios de Hildegard von Bingen y Hroswitha von Gandersheim, ambas religiosas, abadesas y poetas.

Me detendré en Hroswitha y Hildegard porque sus escritos literarios muestran las categorías racionales que comento. Ambas describen, en sus poemas místicos, más estados de conciencia que conceptos y significados objetivos del mundo exterior; su sentido de verdad es simbólico, superior a las meras verificaciones.

En el Prólogo al escrito titulado "Leyenda de María", Hroswitha describe su poema sobre la vida de la Virgen siguiendo el Evangelio de Santiago, y cuenta que, cuando al final descubre que ese evangelio es apócrifo, decide no destruirlo porque lo que hoy puede resultar falso, mañana 
puede resultar verdadero, y todavía añade que la imaginación artística puede ayudar a descubrir la verdad.

Este concepto de verdad, en el siglo $\mathrm{X}$, se anticipa mucho al concepto renacentista y moderno de verdad científica, en donde imaginar hipótesis creativamente implica movilidad y menos fijismo en las cuestiones que pueden variar. Previo a Hroswitha, la ciencia era de lo eterno e inmóvil y se encontraba en la mera contemplación, Hroswitha se aparta del mimetismo de la verdad para proponer una producción creadora que la descubra.

La aportación poemática de este asunto está en la sentencia: la verdad es cambiante y, además, implica imagen y creación. Otra peculiaridad femenina señalada por María Elena, a partir de Hroswitha, es una especie de rebelión de la mujer hacia su condición social, cuya solución nunca implica la salida o cambio de estadio, sino la posibilidad de crear nuevas alternativas dentro de su propia condición. La mujer no deja su condición, sino que forja historia y realidad a partir de lo que ya tiene. Citando a Ida Magli, señala María Elena: "Incluso algunos aspectos más típicos de la ascesis, concedido en el monacato como técnicas de superación de la cultura y de la caducidad histórica, se convierten por las mujeres en caminos positivos de reencuentro con la realidad individuada y autosuficiente, y, como tales, impregnadas de capacidad de hacer historia".

Por eso Hroswitha, en el drama titulado «Fe, Esperanza y Caridad", nos presenta la desesperación del emperador Adriano frente a Esperanza, que prefiere el martirio antes que ofrecer incienso a la diosa impura Diana. 
Adriano y Esperanza representan el contrapunto que Hroswitha quiere resaltar: el emperador es incapaz de entender por qué ella no renuncia a la muerte y persevera en ese mismo camino. Para Adriano, esta decisión no es congruente, le parece antinatural, irracional. Esta valoración de ambas posturas nos manifiesta la diferencia de enfoque entre hombre y mujer: descubre nuevas posibilidades de desarrollo, al afirmar su convicción y aceptar la muerte. Para Esperanza, la muerte no es el fin, y no lo es - no desde una perspectiva sobrenatural o religiosa solamente- sino en cuanto que permanecer en su postura la hace más libre y autónoma. Lo propio de la mujer no es pues la lucha, sino la aceptación consciente y voluntaria de su propia condición, y eso es lo que la hace plenamente humana. Creo que en el análisis de estos poemas está el punto más alto de la tesis del libro y habría que pedir también a María Elena la publicación de las obras de estas autoras.

También en Hildegard von Bingen contemplamos esta particularidad del enfoque gnoseológico femenino. Nos señala María Elena, en la página 186, que incluso acuñó un término "veriditas" (verdor), como conocimiento vital, una palabra que convirtió en concepto; pero el significado profundo del término es representativo del punto que quiero señalar. Para Hildegard, verdor es "fuerza germinante en el movimiento de una rueda que escapa a la inteligencia humana", la superación de la propia condición femenina está al interior de su propio estado. Desde que Hidegard comenzó a escribir poesía, se opuso a Jutta de Spannheim, su maestra. Para Jutta, la intensidad de los significados en los libros era más profunda que la gramática; en cambio, para Hildegard, una vez muerta Jutta, y siendo ella nombrada abadesa, el mundo es mucho más que 
significado en los libros es "la experiencia de una visión". La cito: "Por voluntad divina, mi espíritu, durante la visión asciende hasta las estrellas en una atmósfera diferente, se dilata y se extiende sobre la tierra, en lo alto, sobre diferentes regiones, en lugares alejados de donde quede mi cuerpo".

Otra vez estamos frente a una antropología que implica liberación desde la propia conciencia interior. En su primera obra, Scivias o Ve los caminos, afirma María Elena: "Hildegard se identifica con el papel de los profetas del Antiguo Testamento que no se preocupaban por dar a sus palabras las formas de un discurso ni por adecuarlas conforme a la lógica o la dialéctica. Para ella la clave está en la visión, por eso al final de Scivias escribe: "Entonces vi un aire luminoso en el que escuché ¡oh maravilla!, todas las músicas con todos los misterios que el Señor me había revelado: las alabanzas de júbilo de los ciudadanos celestes que gallardamente perseveraron en la senda de las verdas; y las lamentaciones de cuantos son llamados de nuevo a estos laudes de la alegría. Y aquéllas son, como voz de muchedumbres, que en armonía cantaba las alabanzas de las órdenes celestes"”.

Esta exploración del modo de discurso femenino en la Edad Media, nos lleva a desentrañar la peculiar psicología de la mujer, así como sus caracteres y formas de racionalidad. La contribución de María Elena y su obra empujan al lector a rastrear fuentes directas de los siglos X al XIII, para continuar penetrando en esas formas de discurso. Es así que la obra cumple con un objetivo clave: llevar al lector a un estudio directo y analítico de las fuentes primarias de la época. 


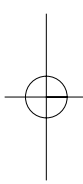

